\title{
高温高圧水を供給するヒートポンプの乾燥工程への適用*
}

\author{
梅沢 修一 ${ }^{* 1}$, 上田 憲治 ${ }^{* 2}$, 福島 亮*2 \\ 甘利 治雄 ${ }^{* 3}$, 島田 寛之 ${ }^{* 3}$, 松久 高士 ${ }^{* 4}$

\section{Application Study of a Heat Pump Producing High Temperature and High Pressure Water for an Industrial Drying Process}
Shuichi UMEZAWA ${ }^{* 1}$, Kenji UEDA, Ryo FUKUSHIMA, Haruo AMARI, Hiroyuki SHIMADA and Takashi MATSUHISA \\ ${ }^{* 1}$ Tokyo Electric Power Company, 4-1 Egasaki-cho, Tsurumi-ku, Yokohama, 230-8510 Japan \\ This paper reports application study of newly developed turbo heat pump for $130^{\circ} \mathrm{C}$ water for an industrial process \\ in an actual factory. The heat pump is characterized by high efficiency and large heat output, by using a state-of-the-art \\ turbo compressor. The heat pump requires a low temperature heat source. The heat demand is for several drying \\ furnaces in the factory, which requires producing hot air of $120^{\circ} \mathrm{C}$. The heat exchanger was designed to produce the hot \\ air. Experiments were conducted to confirm the performance of the heat exchanger with a reduced size of the heat \\ exchanger. Low temperature heat sources are from both exhaust gas of the drying and annealing furnaces. The heat \\ exchangers were also designed to recover heat of the exhaust gas. As a result, it was confirmed that the heat pump was \\ able to satisfy the present heat demand while retaining high efficiency.
}

Key Words : High Temperature, Industrial Process, Heat Recovery, $\mathrm{CO}_{2}$ Emission Reduction

\section{1. 緒言}

近年，産業分野における省エネルギーと $\mathrm{CO}_{2}$ 排出削減は重要な課題であり，ますます関心を集めている．電気 式ヒートポンプは高い省エネ性を有しているが，これまで $100^{\circ} \mathrm{C}$ 以上の温熱を生成することが困難であり，産業 分野のエネルギー消費として大きな比率を占める $100^{\circ} \mathrm{C}$ 以上の熱需要は, 主にボイラにより供給されてきた. 今 回, 我々はボイラ代替としてこの高温域の熱需要に対応するために, $130^{\circ} \mathrm{C}$ 高温高圧水を生成するヒートポンプ を開発し, 実際の変圧器製造工場の乾燥工程に対して適用研究を実施した. ヒートポンプの熱源に, 工場排熱を 有効利用すること等の周辺技術も検討し, 本ヒートポンプ導入による省エネ効果と $\mathrm{CO}_{2}$ 削減効果を検証した.

\author{
A: Heating surface area $\left[\mathrm{m}^{2}\right]$ \\ $d$ : Diameter of tube [m] \\ $G$ : Mass flow rate $[\mathrm{kg} / \mathrm{s}]$ \\ $K$ : Overall heat transfer coefficient $\left[\mathrm{W} / \mathrm{m}^{2} \mathrm{~K}\right]$ \\ $T$ : Temperature $\left[{ }^{\circ} \mathrm{C}\right]$ \\ $W$ : Thermal energy, Electric energy $[\mathrm{J} / \mathrm{s}]$ \\ $\lambda$ : Heat conductivity $[\mathrm{W} / \mathrm{m} \mathrm{K}]$ \\ Subscript \\ elec-in: Electricity input
}

\section{2. 記号 - 単位}

$C$ : Heat capacity $[\mathrm{J} / \mathrm{kg} \mathrm{K}]$

COP: Coefficient of performance of heat pump [-]

$h$ : Enthalpy [J/kg]

$\mathrm{Nu}$ : Nusselt number [-]

$V$ : Volume $\left[\mathrm{m}^{3}\right]$

$\alpha$ : Heat transfer coefficient $\left[\mathrm{W} / \mathrm{m}^{2} \mathrm{~K}\right]$

$\rho$ : Density $\left[\mathrm{kg} / \mathrm{m}^{3}\right]$

exchange: Heat exchange

\footnotetext{
*原稿受付 2011 年 8 月 15 日

*1 正員, 東京電力 (株) (厂230-8510 神奈川県横浜市鶴見区江ヶ崎町 4-1)

*2 正員, 三菱重工業(株)

*3 東京電力 (株)

*4 (株) 高岳製作所

E-mail: umezawa.s@tepco.co.jp 
gas: Gas

go: Gas outlet from heat exchanger

i: Inside of heat exchanger

o: Outside of heat exchanger

water-in: Water inlet to heat pump

wi: Water inlet to heat exchanger gi: Gas inlet from heat exchanger

heatpump-out: Heat pump output

metal: Metal tube of heat exchanger

water: Water

water-out: Water outlet from heat pump

wo: Water outlet from heat exchanger

\section{3. $130^{\circ} \mathrm{C}$ 温水生成用ヒートポンプ}

今回新たに開発した $130^{\circ} \mathrm{C}$ 高温高圧水生成ヒートポンプの概念図を図 1 に示す. 圧縮機に半密閉型ターボ圧縮 器を採用することにより高効率大容量を実現した，圧縮機翼は二段圧縮式で，一段目と二段目ともに炭素鋼製で あり，回転数は最大 $700 \mathrm{~Hz}$ まで達する. 作動流体は HFC134a を用い， $70^{\circ} \mathrm{C}, 1.2 \mathrm{MPa}$ （圧縮機入口）から $145^{\circ} \mathrm{C}$, 5.0MPa（圧縮機出口）まで圧縮する。 なお, 圧縮機出口において HFC134a は超臨界流体（臨界温度 $101.15^{\circ} \mathrm{C}$, 臨界圧力 $4.06 \mathrm{MPa})$ となる ${ }^{(1)}$. ヒートポンプは出口水温 $130^{\circ} \mathrm{C}$, 負荷からの戻り水である入口水温は $70^{\circ} \mathrm{C}$, そし て最大負荷時の水量は $2.48 \mathrm{~kg} / \mathrm{s}$ で動作する.この際の出力は $627 \mathrm{~kW}$ となり, これは約 $1000 \mathrm{~kg} / \mathrm{h}$ の蒸気熱量に相 当する. また，本ヒートポンプは工場内の排熱を回収することにより得られた $55^{\circ} \mathrm{C}, 21.9 \mathrm{~kg} / \mathrm{s}$ の温水を低温熱源 として利用している. この時の HFC134a の蒸発器における蒸発温度は $48^{\circ} \mathrm{C}$ である. 蒝発器を出た HFC134a は圧 縮流入前に設置されたインタークーラにおいて $130^{\circ} \mathrm{C}$ 温水生成熱交換器を出た HFC134a から受熱することにより, $\mathrm{COP}=3$ を達成するように設計された.
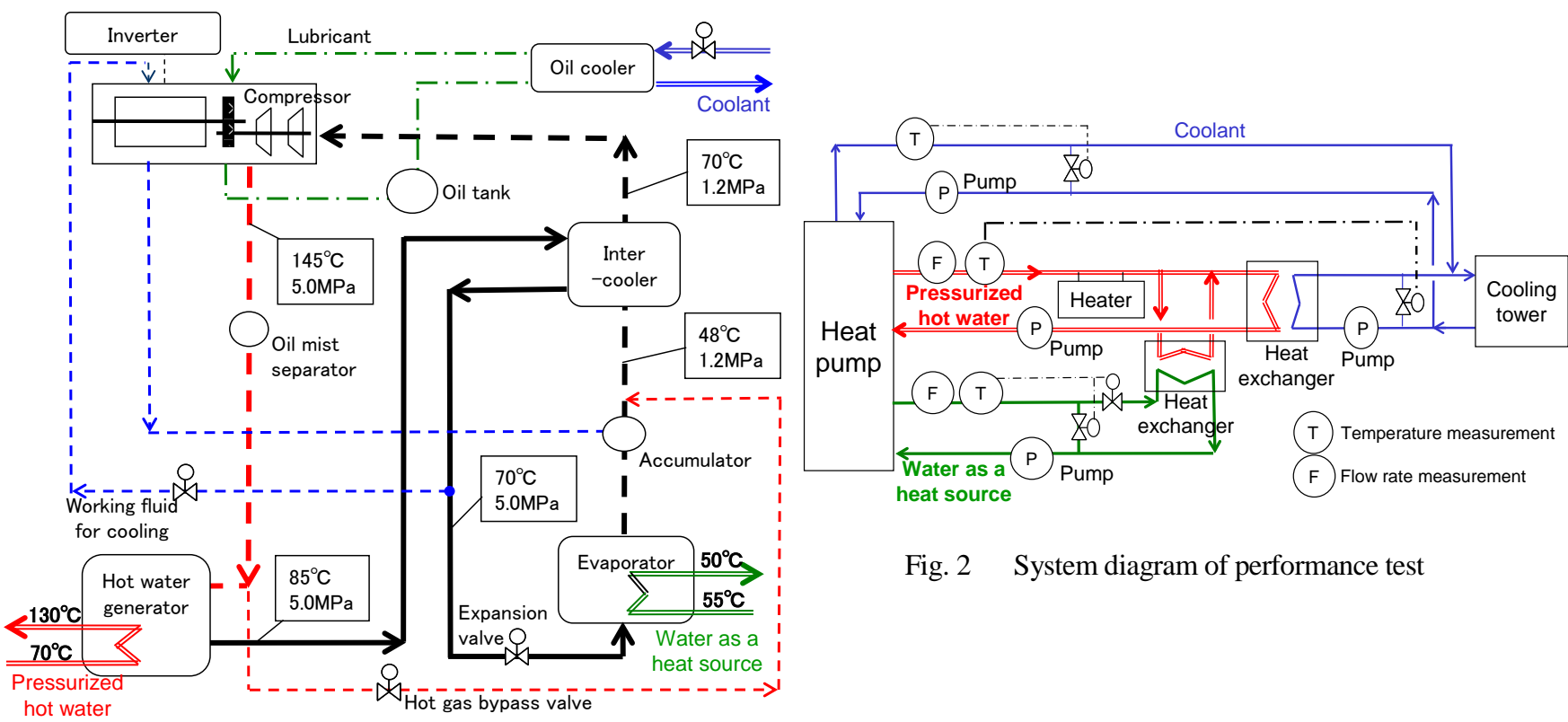

Fig. 2 System diagram of performance test

Fig. 1 Heat pump for $130{ }^{\circ} \mathrm{C}$ water

次に，ヒートポンプの単体性能を実証する試験を行った．図 2 に実証試験のシステム概念図を示す.ヒートポ ンプからの出力は, 主に熱源水生成に使用し, 余剩熱を邻却塔で処理することにより, システムの熱バランスを 成立させた. システム内に設置されたヒータは，ヒートポンプ立上げ時の熱源確保用である．性能試験の結果， $130^{\circ} \mathrm{C}, 627 \mathrm{~kW}$ 温水生成時に, 式(1)を用いた試算で $\mathrm{COP}=3$ を実証することができた.

$C O P=\frac{W_{\text {heatpump-out }}}{W_{\text {elec-in }}}=\frac{\left(h_{\text {water-out }}-h_{\text {water-in }}\right) \cdot G_{\text {water }}}{W_{\text {elec-in }}}$ 


\section{4. 実エ場における熱需要計測}

変圧器製造において, 変圧器の絶縁性を保つため, 約 $120^{\circ} \mathrm{C}$ で十分に乾燥させる必要がある. ヒートポンプ導 入前の乾燥システム概念図を図 3 に示寸. 乾燥のための昇温は蒸気により行われ, 蒸気は $2000 \mathrm{~kg} / \mathrm{h}$ ボイラによっ て生成されていた，本工場には乾燥炉の他に，焼鈍炉も併設されており，これらの炉から出される排気ガスは煙 突より大気に放出されていた。 ヒートポンプ導入のためには，システムにおける熱需要量と排熱量のバランスが 重要な要素となる. そこで, 本ヒートポンプ導入においても, その初期検討として工場内の乾燥工程の熱需要量 と乾燥炉と焼鈍炉からの排熱量の計測を行った. 計測の結果, 表 1 に示されるように, 需要側熱量は650kWであ った. しかしながら, 乾燥炉の熱交換器から凝縮することなく排出される蒸気が目視により確認されたことから,

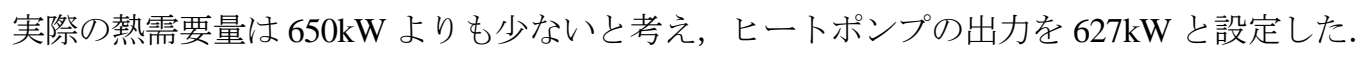

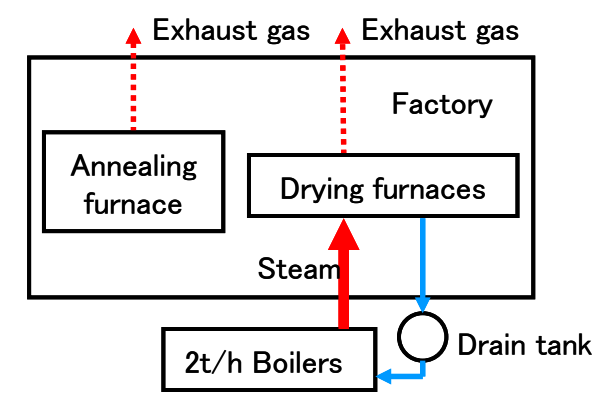

Fig. 3 Drying system before heat pump

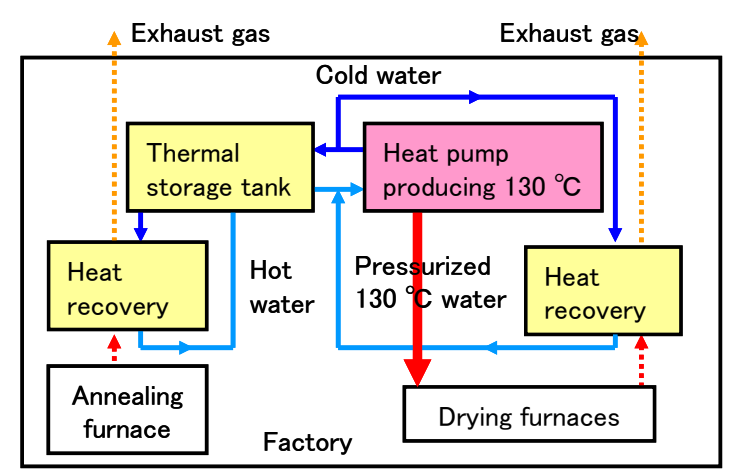

Fig. 4 Drying system after heat pump
Table 1 Measurement results of thermal demand of drying furnace installation

\begin{tabular}{|c|c|c|}
\hline & & Note \\
\hline Steam flow rate & $880 \mathrm{~kg} / \mathrm{hour}$ & Annual average \\
\hline Pressure of steam & $0.5 \mathrm{MPa}$ & Saturated steam \\
\hline Thermal value of steam & $650 \mathrm{~kW}$ & \\
\hline
\end{tabular}

Table 2 Measurement results of thermal value of exhaust gas from the drying furnaces and that from the annealing

furnace installation

\begin{tabular}{|c|c|c|}
\hline & & Note \\
\hline $\begin{array}{c}\text { Temperature of exhaust gas } \\
\text { from drying furnaces }\end{array}$ & $115^{\circ} \mathrm{C}$ & $\begin{array}{c}\text { Heat is recovered up } \\
\text { to } 55^{\circ} \mathrm{C} .\end{array}$ \\
\hline $\begin{array}{c}\text { Flow rate of exhaust gas from } \\
\text { drying furnaces }\end{array}$ & $5 \mathrm{~m}^{3} / \mathrm{s}$ & $\begin{array}{c}\text { In consideration of } \\
\text { design }\end{array}$ \\
\hline $\begin{array}{c}\text { Thermal value of exhaust gas } \\
\text { from the drying furnaces }\end{array}$ & 300 \\
\hline $\begin{array}{c}\text { Temperature of exhaust gas } \\
\text { from the annealing furnace }\end{array}$ & $115^{\circ} \mathrm{C}$ & $\begin{array}{c}\text { The heat is recovered } \\
\text { until } 55^{\circ} \mathrm{C} .\end{array}$ \\
\hline $\begin{array}{c}\text { Flow rate of exhaust gas from } \\
\text { the annealing furnace }\end{array}$ & $2 \mathrm{~m}^{3} / \mathrm{s}$ & \\
\hline $\begin{array}{c}\text { Thermal value of exhaust gas } \\
\text { from the annealing furnace }\end{array}$ & $\begin{array}{c}120 \\
\mathrm{~kW}\end{array}$ & \\
\hline
\end{tabular}

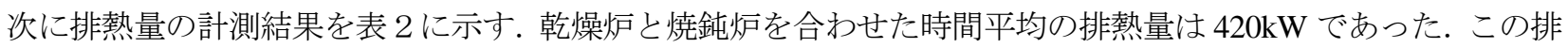
熱量が常時得られればヒートポンプがフル稼働する熱源として十分な熱量であるが，実際には炉の稼働状況によ って，排熱量は変化する，具体的には，本工場における炉の稼動は，乾燥炉が夜間運転，焼鈍炉が昼間運転とな っている. そこで, 図4 に示すように, 乾燥炬における熱需要量と排熱量の時差を埋めるために蓄熱槽を設け, そのことを考慮しての試算の結果, 熱需要量を満たす排熱量を得られることが判った. 以上を基に, 本乾燥工程 へのヒートポンプ導入が可能であると判断された.

\section{$5 \cdot 1$ 乾燥炉用温風生成熱交換器}

\section{5. ヒートポンプ周辺技術の検討}

乾燥炉用熱交換器はヒートポンプにより生成された $130^{\circ} \mathrm{C}$ 高圧水から, $125^{\circ} \mathrm{C}$ の乾燥用温風を発生するもので ある. 本熱交換器の各部温度と圧力を表 3 に示寸. 工場に乾燥炉は 8 台あり, 1 台あたりの乾燥炉が要求する熱 量は約 $80 \mathrm{~kW}$ である. また，コンパクト化を目的に，対向流フィンチューブ熱交換器を採用した．実機作製前の 前段実証試験として, $10 \mathrm{~kW}$ 熱交換器を試作し, その性能評価を行った。 $10 \mathrm{~kW}$ 熱交換器の外観を図 5 に, 試験装 置全体の概念図を図 6 示寸. $10 \mathrm{~kW}$ 熱交換器は, 実機となる $80 \mathrm{~kW}$ 乾燥炉用熱交換器の前面面積のみを $1 / 8$ に縮尺 したものであり, 実機と同様の熱通過率 $\left(420 \mathrm{~W} / \mathrm{m}^{2} \mathrm{~K}\right)$ を有している. $130^{\circ} \mathrm{C}$ 高温高圧水は, $15 \mathrm{~kW}$ 電気ヒータに 
よる加熱と，窒素ボンベによる加圧により得た，空気をファンにより熱交換器へと送り込み，その入口流量を差 圧計により測定し，各部の温度を熱電対により測定した。

Table 3 Temperature and pressure of the heat

\begin{tabular}{|c|c|c|}
\hline & Temperature & Pressure \\
\hline Water inlet & $130^{\circ} \mathrm{C}$ & $0.5 \mathrm{MPa}$ \\
\hline Water outlet & $70^{\circ} \mathrm{C}$ & $0.5 \mathrm{MPa}$ \\
\hline Air inlet & $20^{\circ} \mathrm{C}$ & $0.1 \mathrm{MPa}$ \\
\hline Air outlet & $125^{\circ} \mathrm{C}$ & $0.1 \mathrm{MPa}$ \\
\hline
\end{tabular}

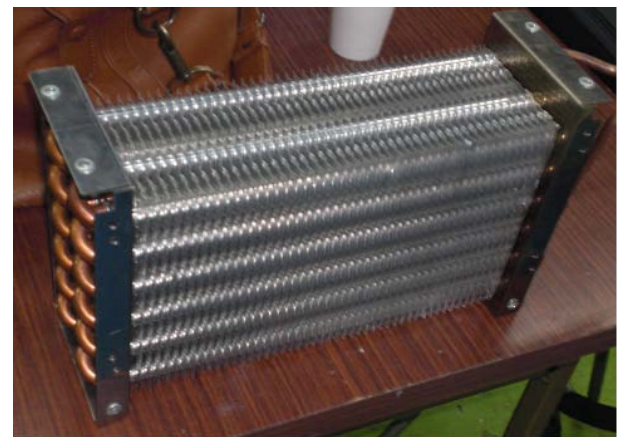

Fig. $510 \mathrm{~kW}$ test model heat exchanger exchanger

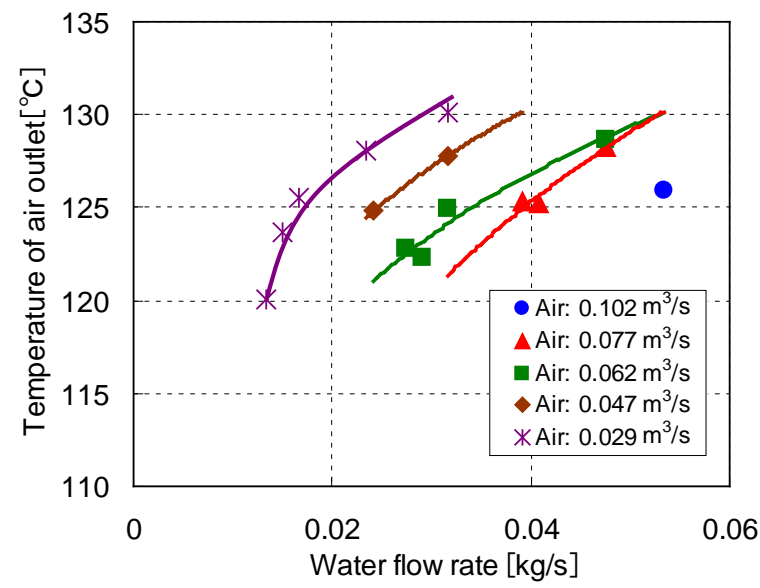

(a) Temperature of air outlet

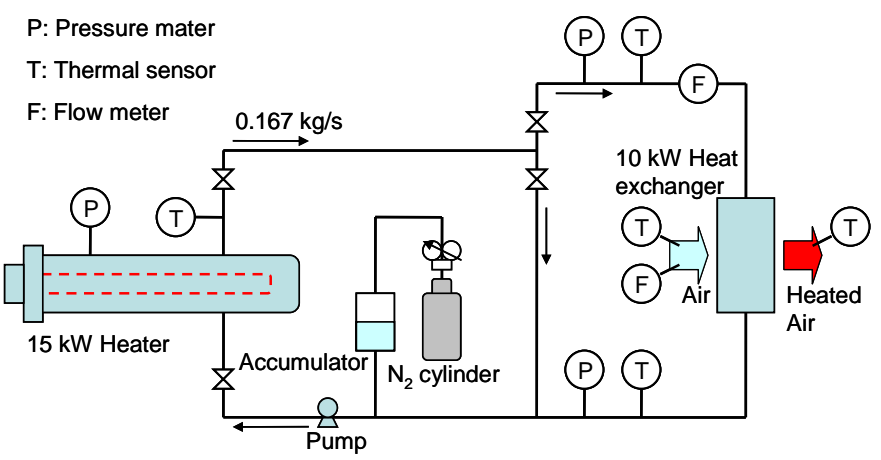

Fig. 6 Schematic of performance evaluation apparatus of test model heat exchanger

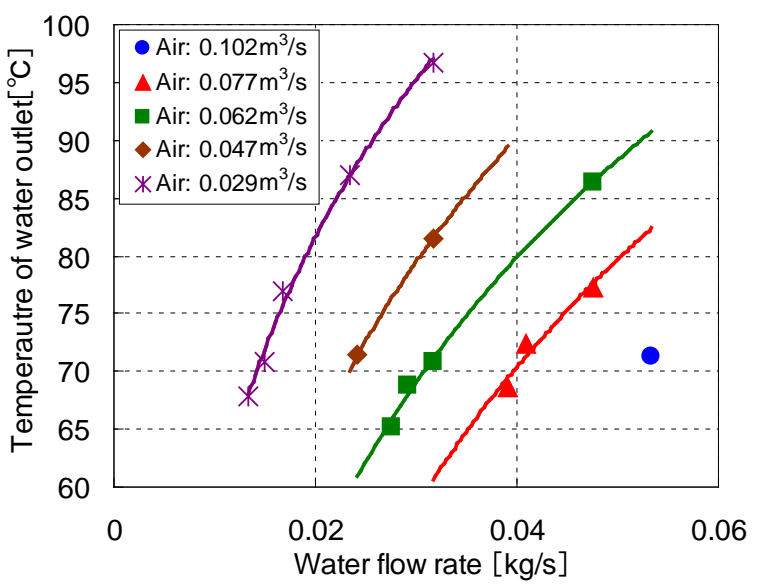

(b) Temperature of water outlet

Fig. 7 Outlet temperature of test mode heat exchanger as a function of water flow rate

熱交換器の空気出口温度と水量の関係を図 7 (a)に，温水出口温度と温水量の関係を図 7 (b)に示す. 温水量が増 加するに伴い, 空気出口温度と温水出口温度は上昇する。ここで本試験の目標としている温度は，空気出口温度 $125^{\circ} \mathrm{C}$ と温水出口温度 $70^{\circ} \mathrm{C}$ を同時に満たすことである. 図 8 より，空気流量 $0.047 \mathrm{~m}^{3} / \mathrm{s}$ 以上であれば，温水流量 を最適化することにより，目標の運転が実現できることが判った．なお，空気流量 $0.029 \mathrm{~m} / \mathrm{s}$ 時に，空気出口温度 を $125^{\circ} \mathrm{C}$ とすると温水出口温度が $75^{\circ} \mathrm{C}$ 以上に上昇してしまう結果であったが，この空気流量域は実機において 想定される動作範囲から外れているため, 問題はないと考えられる. 熱通過率は空気流量 $0.077 \mathrm{~m}^{3} / \mathrm{s}$, 水量 $0.041 \mathrm{~kg} / \mathrm{s}$ 時， $414 \mathrm{~W} / \mathrm{m}^{2} \mathrm{~K}$ となり，設計值とほぼ同等となる.

\section{$5 \cdot 2$ 乾燥炉からの排熱回収}

工場排熱を熱源として用いる場合，生産工程中に発生した不純物により，排熱回収用熱交換器の性能を低下さ せることが懸念される(2). 従って実機導入前に, 実工場において乾燥炉排ガスからの排熱回収効率の経時変化を 9 ヶ月間連続で計測した. 排熱回収用熱交換器は, 実機 $300 \mathrm{~kW}$ に対して $6.7 \mathrm{~kW}$ に縮小したフィンチューブ熱交換 器を使用し, ガス側熱伝達率 $27 \mathrm{~W} / \mathrm{m}^{2} / \mathrm{K}$ は実機と同值とした. 動作環境を表 4 に, 試験装置の概念図を図 8 に示 す．乾燥炉からの排気ガスがファンにより熱交換器に導かれ，水により冷却される. 熱交換器排ガスの出入口温 
度と風量, 冷却水の出入口温度を測定し，出口風量を式(2)より，熱交換器ガス側の熱伝達率（面積管内基準）を 式(3)より求めた。 なお，9ケ月後は排気ファンの回転数を調整し，排ガス風量を設計点の倍以上に増加させた.

図 9 に示されるように，ガス側熱伝達率は排気ガス流量とともに増加した。 測定された熱伝達率を「開始〜4 ケ月」,「5〜6 ケ月」,「7〜9 ケ月」の 3 期間に分け比較したところ, 「7〜9 ケ月」においても際立った性能低下は 観測されなかった. また, 本熱交換器は設計值である $6.7 \mathrm{~kW}$ (ガス流量 $0.16 \mathrm{~m}^{3} / \mathrm{s}$ 時) よりも高い性能を示し, $110^{\circ} \mathrm{C}$ の排気ガスが $5.1 \mathrm{~m}^{3} / \mathrm{s}$ の流量があれば $300 \mathrm{~kW}$ を回収できることが判った。本乾燥工程からの排気ガスは上記条件 を満たしていたことから，フィンチューブ熱交換器による乾燥工程からの排熱回収の実現性を確認できた.

$$
\begin{aligned}
& W_{\text {exchange }}=C_{\text {water }} G_{\text {water }}\left(T_{\text {wo }}-T_{\mathrm{wi}}\right), \quad V_{\mathrm{go}}=\frac{W_{\text {exchange }}}{\left(T_{\mathrm{gi}}-T_{\mathrm{go}}\right) \cdot C_{\mathrm{go}} \cdot \rho_{\mathrm{go}}} \\
& W=K A \Delta T_{m}, \quad \alpha_{i}=\frac{N u_{i} \cdot \lambda_{w}}{d_{i}}, \quad N u_{\mathrm{i}}=0.023 \operatorname{Re}^{0.8} \operatorname{Pr}^{0.4}
\end{aligned}
$$

Table 4 Temperature and pressure of the heat

\begin{tabular}{|c|c|c|}
\hline & Temperature & Pressure \\
\hline Water inlet & $50^{\circ} \mathrm{C}$ & $0.1 \mathrm{MPa}$ \\
\hline Water outlet & $55^{\circ} \mathrm{C}$ & $0.1 \mathrm{MPa}$ \\
\hline Exhaust gas inlet & Approximately $115^{\circ} \mathrm{C}$ & $0.1 \mathrm{MPa}$ \\
\hline Exhaust gas outlet & $55^{\circ} \mathrm{C}$ & $0.1 \mathrm{MPa}$ \\
\hline
\end{tabular}

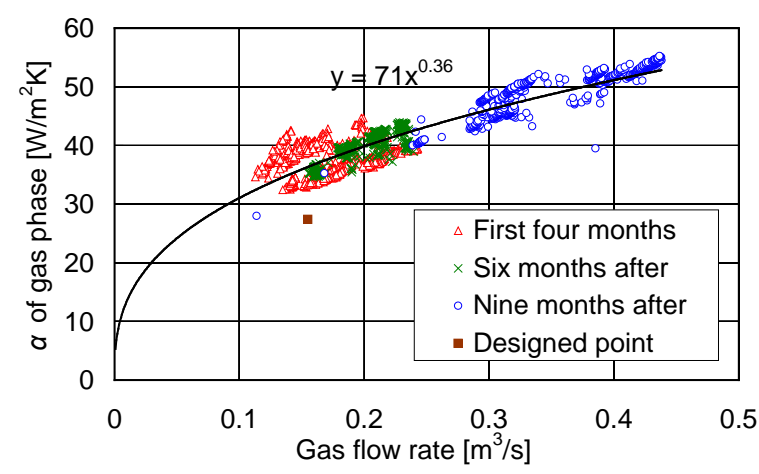

Fig. 9 Heat transfer coefficient as a function of gas

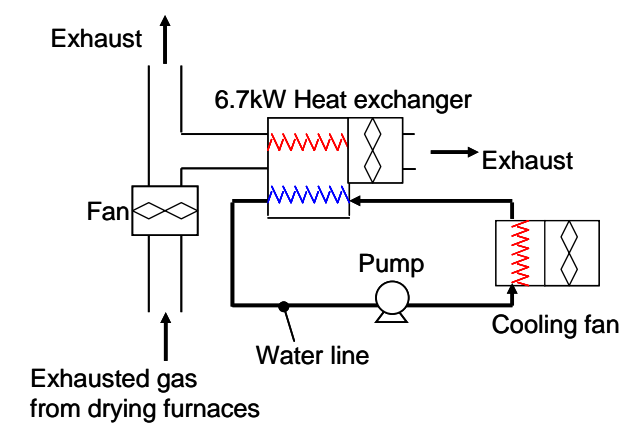

Fig. 8 Schematic of heat recovery investigation

Table 5 Primary energy and the $\mathrm{CO}_{2}$ emission of the heat pump and boiler in actual factory

\begin{tabular}{|c|c|c|}
\hline & Boiler & Heat pump \\
\hline Primary energy consumption & $13.7 \mathrm{TJ} /$ year & $9.79 \mathrm{TJ} /$ year \\
\hline Ratio of reduced primary energy & $100 \%$ & $71.5 \%$ \\
\hline $\mathrm{CO}_{2}$ errission & $666 \mathrm{t} /$ year & $332 \mathrm{t} /$ year \\
\hline Ratio of reduced $\mathrm{CO}_{2}$ emission & $100 \%$ & $49.8 \%$ \\
\hline
\end{tabular}

\section{6. ヒートポンプ導入による省エネ・ $\mathrm{CO}_{2}$ 削減効果}

今回の実証試験より得られた結果を基に, 乾燥工程における一次エネルギー消費量と $\mathrm{CO}_{2}$ 排出量について, ヒ 一トポンプとボイラの比較を行った．結果を表 5 に示す. 前提条件は, 電力電源効率 $36.9 \%, C O P=2.5$ (部分負 荷を考慮), ヒートポンプ平均負荷率 $80 \%$ ，ボイラ効率 $86 \%$ ，ボイラ負荷間の配管損失 $20 \%$ （ ${ }^{(3)}$ ，ボイラ燃料熱量， $45 \mathrm{MJ} / \mathrm{m}^{3} \mathrm{~N}, \mathrm{CO}_{2}$ 排出量は電力とボイラ燃料それぞれ $0.332 \mathrm{~kg}-\mathrm{CO}_{2} / \mathrm{kWh}$ と $2.19 \mathrm{~kg}-\mathrm{CO}_{2} / \mathrm{m}^{3} \mathrm{~N}$ とした.

\section{7. 結語}

ターボ圧縮機を用いた $130^{\circ} \mathrm{C}$ 高温高圧水を生成するヒートポンプを開発し, 実工場導入について検討を行った. ヒートポンプは COP=3 であり，実工場における調査・測定の結果，ヒートポンプ適用の実現性を確認すること ができた．現在，本検討に基づき，実際にヒートポンプは実工場設備として導入が進行中であり，その稼動時に は, 約 3 割の省エネルギーと 5 割の $\mathrm{CO}_{2}$ 排出削減を実現することが期待できる.

\section{文献}

(1) 佐藤春樹, Thermodynamic Properties of Pure and Blended Hydrofluorocarbon Refrigerants (1998), 日本冷凍空学会.

（2）梅沢修一，島田寛之，甘利治雄，櫻井浩治，日本機械学会 2010 年度年次大会，(2010), p.123.

（3）梅沢修一, 甘利治雄, 安田仁, 川村仁, 加藤収三, 久世勝彦, 日本機械学会 2010 年度年次大会, (2010), p.3. 